
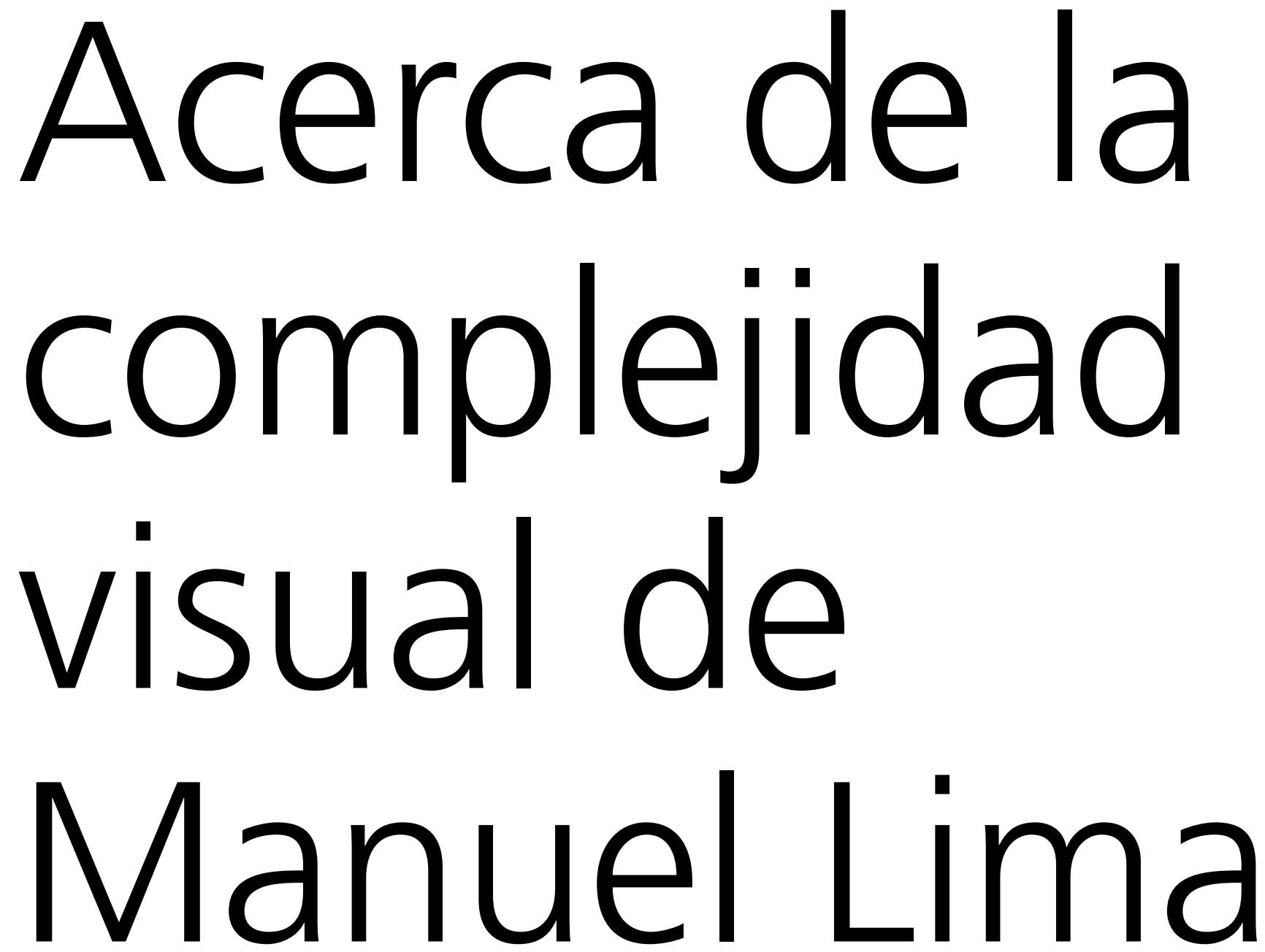

Alejandra Barroeta

Barroeta, A. (2015). Acerca de la Complejidad Visual de Manuel Lima. Economía Creativa. (04) otoño-invierno 2015, México: pp. 140-150. 


\section{Acerca de la complejidad visual de Manuel Lima}

Alejandra Barroeta ${ }^{1}$

Complejidad visual (Visual complexity) es una publicación de Manuel Lima, diseñador portugués, que se adentra en el mundo de la administración de la información desde la perspectiva de cómo los patrones visuales están por convertirse en una innovación característica del siglo XXI por el valor añadido que otorga la representación visual a las grandes cantidades de información generada tal como la fotografía representó una disrupción para la humanidad en el siglo XX.

Este libro aborda cómo las sociedades han aprendido a administrar el conocimiento existente y distribuirlo de una manera eficiente, empezando desde diagramas de árbol hasta las necesidades actuales de priorización de datos creados en distintos espectros cuyos fundamentos se basen en sociedades del conocimiento e inteligencia colectiva.

Una de las representaciones más antiguas de sistemas es entonces el árbol de la vida, esquema finito organizacional jerárquico conocido como un instrumento de representación que ha cubierto desde campos teológicos hasta científicos, siendo así además de un mecanismo analítico, una metáfora que representa el origen del Universo como un mapa de nuestra existencia, conectando las raíces existentes con una serie de implicaciones de categorías subordinadas, lo cual resulta en una clasificación seriada de relaciones que resulta ante el ojo humano como un orden comprensible.

Francis Bacon, filósofo inglés y promotor ferviente de la Revolución Científica del siglo XVI, definió al árbol del conocimiento como: 
Las distribuciones y partituras del conocimiento no son líneas que se encuentran en un ángulo y se tocan en un punto, sino ramificaciones de un árbol que se encuentran en un tallo, el cual dimensiona y cuantifica la totalidad y continuidad, antes de que se vuelva discontinuo y se rompa a sí mismo en brazos y ramas (Bacon).

Manuel Lima considera que a través de declaraciones de Bacon y Descartes es como se logra la consolidación y uso de esta herramienta en la sociedad, que si bien ambos no fueron diseñadores visuales, sí lograron contribuir decisivamente -a través de sus palabras- al establecimiento formal del modelo epistemológico.

Posterior al orden que se obtuvo de los diagramas de árbol, apareció la enciclopedia como resultado del deseo de reunir el conocimiento humano existente en un compendio comprensible y organizado; para el siglo XVIII las enciclopedias ya habían incluido a los árboles dentro de diferentes ramas de estudio pasando desde Geometría hasta Ciencias de la Vida y filosofía. Es así como las tablas de contenido nacen y la primera aparición impresa fue en el año 1728, como parte del prefacio de la Cyclopedia, o del Diccionario universal de artes y ciencias.

A pesar del simbolismo e innegable utilidad de los diagramas de árbol / árboles de la vida, conforme su uso se fue generalizando aparecieron diversas críticas ante su funcionalidad rígida y atributos limitados, principalmente por su falta de flexibilidad por ser un modelo que careciera de facilidad de interconectividad lo cual afectaba las mutaciones contantes que ocurren como resultado de envolver a un amplio número de variables relacionables en coexistencia.

La narración describe cómo el ser humano en distintos ambientes funciona a través de sistemas complejos que requieren estar interrelacionados para su funcionamiento; partiendo de este contexto, el autor narra tres ejemplos prácticos: el primero, la construcción de ciudades que han logrado evolucionar y romper las barreras del pensamiento rígido e insípido para lograr desarrollos urbanos orgánicos que permitan la coexistencia de las actividades sociales en módulos interconectados que resultan ante la convivencia de la sociedad que per se es ambigua, compleja e idiosincrática, de tal forma que se logran satisfacer sistemas 
amigables a partir de retículos y no árboles; el segundo, la colaboración social ejemplificada desde la comunicación entre equipos de trabajo hasta sociedades que pueden funcionar bajo esquemas centralizados (gobierno-empresas-ciudadanos) comparado a esquemas sin jerarquización en donde la cooperación ocurre de manera natural con transparencia e incluso independencia constructiva que promueve la descentralización; y el tercero, cómo el cerebro humano realiza el proceso de sinapsis, a través del cual se logran vínculos entre neuronas las cuales producen una mejor comunicación en lugar de realizar intercambio de información de una a otra, lo cual resulta en mejores funciones cerebrales que no están relacionadas una a una sino mediante puentes continuos. Todos estos casos prácticos ayudan a la comprensión de cómo se realizó una evolución visual de árboles a redes para lograr ese vínculo que trascienda barreras de tiempo o espacio geográfico.

El desarrollo de redes se permea por su existencia "omnipresente"; su modelo estructural y organizado en cada sujeto lo cual dio nacimiento a una ciencia que estudiase el trabajo colaborativo en redes, siendo Leonhard Euler en 1736, matemático alemán, pionero de las representaciones gráficas de vínculos interconectados que vio más allá de una serie de puentes aislados. Así es como se inicia el uso especializado en ciencias exactas, pasando de métodos matemáticos a estudios sobre geografía psicológica hasta llegar a nuevas ramificaciones como lo fueron las cartografías.

Representar de manera gráfica la evolución del pensamiento humano así como adaptarse al incremento constante de la información generada ha sido una dinámica disruptiva de acuerdo a las herramientas disponibles -altamente ligadas con la tecnología- de tal manera que nuevas formas de graficar el acomodamiento de puntos y su vínculo entre ellos ha resultado en una era de interconectividad infinita. Nunca antes el hombre había vivido un sentido de interdependencia con el mundo a un nivel altamente interrelacionado; bien describe Bruce Mau, diseñador canadiense, "Cuando todo se encuentra conectado a todo, para bien o para mal, todo sucede".

Manuel Lima expone una serie de herramientas y modelos visuales que se han desarrollado en distintos contextos para satisfacer la búsqueda constante de un acomodo visual apropiado a distintas necesidades, por lo cual algunos ejemplos ilustrados en la obra son: 
- Blogósfera: cambia el flujo de la información en línea y provee un laboratorio para investigar cómo la información se permea a través de comunidades sociales en línea.

- Citas / referencias bibliográficas: una práctica común en publicaciones académicas que respeta los derechos de autor se ha convertido - gracias a los análisis de representación visual- en una importante medida sobre la popularidad y credibilidad a través de círculos escolares. Esto es gracias a que las citas permiten administrar grandes cantidades de libros y documentos de trabajo creando matrices de asociación y ensalzando la proximidad a través de dominios. Lima describe que si dos trabajos son citados por un tercero, la conexión podrá ser inferida entre los dos primeros, aun cuando no exista citación entre ambos.

- Sistemas sociales de marcación: Métodos de visualización de etiquetas digitales que permiten mejorar el proceso de recuperación o simplificar el descubrimiento de sus propios comportamientos; evita la confusión entre cantidades vastas de etiquetas (Ej.: Del.icio.us).

- Donaciones: El creciente acceso a datos gratuitos ha impulsado la transparencia de ambientes políticos o ambientales, ya sean organizaciones conocidas o no, a través de trabajos de investigación y visualización que buscan compartir de manera abierta los resultados de análisis de datos.

- Email: Es uno de los canales de comunicación más importantes en la sociedad moderna; para comprender mejor los hábitos y los patrones de comportamiento social, algunos autores han representado las relaciones entre individuales al examinar los flujos (remitente, receptor, copia de carbón, etc.)

- Internet: Los esquemas gráficos son el primer paso del conocimiento y comprensión de la estructura; conocer cómo funcionan las amplias redes de servidores y routers ha resultado en diferentes facetas de mapas multidimensionales.

- Literatura: Cualquier texto presenta una serie de relaciones entre las líneas de palabras. Mapear el encuentro entre oraciones particulares podría resultar en el descubrimiento del estilo narrativo del autor o incluso de asociaciones escondidas entre los sujetos participantes. Observar con detenimiento las representaciones gráficas de cómo se entrelazan simples 
"palabras" a partir de su desenvolvimiento en oraciones de tal forma que adquieren fortaleza en temas específicos pudiera favorecer el proceso cognoscitivo no sólo de una persona hacia un tema en particular, sino del tema mismo por medio de distintos grupos sociales.

- Música: Como un nuevo campo de la aplicación de visualización de redes, la música se ha convertido en una rama de estudio que, a través de las representaciones gráficas, reconoce afinidades musicales, hábitos personales de interpretación así como interacciones entre géneros, letras, frecuencias, entre otros.

- Noticias: Los medios de comunicación -en conjunto de todas sus formas y canales- son un jugador central en la sociedad contemporánea caracterizada por su saturación de información. Las organizaciones se han tenido que reinventar para poder operar de manera interna las grandes cantidades de acontecimientos que se generan día a día y se convierten en noticias; las herramientas digitales proveen de capacidades extendidas a los medios para poder mapear las relaciones entre las organizaciones y las personalidades que son mencionadas en historias que cubren los reportajes.

- Proteínas: En otro campo de estudio, pero no más reciente, se encuentran las interacciones entre redes de las proteínas, ya que para las ciencias biológicas la comprensión de las interacciones de las estructuras son cruciales para cualquier función de las células vivientes.

- Terrorismo: Caracterizado por la idiosincrasia social, las células terroristas retan al sistema para ser descifradas. En el libro se ejemplifican cinco diagramas:

1 Gráfico tridimensional de las asociaciones de búsquedas frecuentes entre términos asociados con la lucha anti terrorismo en una base de datos (Strausfeld, 2006).

2 Mapa de las actividades globales y afiliaciones asociadas con el terrorismo (Bunting, 2008).

3 Visualización de conexiones sospechosas entre terroristas envueltos en los ataques del 11 de Septiembre (Heer, 2004). 
4 Imágenes de una aplicación interactiva que provee un punto de partida gráfico de la red de Al Qaeda (FMS Advanced Systems Group, 2005).

5 Mapa de interconexiones entre miembros de la red terrorista Al Qaeda (FMS Advanced Systems Group, 2005).

- Trayectorias: Numerosos autores se encuentran mapeando las redes individuales a través de distintas herramientas digitales gratuitas que permiten conocer la geolocalización de seres en particular lo cual resulta en una cartografía social capaz de explorar diferentes facetas de trayectorias específicas.

- Twitter: Esta red social que surge a través de servicios de micro blogs capta información constante a través de una base de usuarios crecientes que envían mensajes de texto hasta de 140 caracteres (tweets) lo cual ha permitido a los creadores el establecer un laboratorio de investigación del comportamiento social de los grupos como una gran herramienta de conocimiento de tendencias y análisis de las fluctuaciones de la opinión pública en tiempo real.

- Wikipedia: Conocida como la enciclopedia más grande que jamás haya antes existido en la historia de la humanidad, posee un cuerpo denso de información almacenada, conectada por millones de hipervínculos que permiten solidificar los patrones.

Los ejemplos anteriores únicamente son parte de una gran variedad de técnicas visuales que permiten atender distintos tópicos y sujetos. La capacidad de generar una técnica que sea exitosa para el usuario final reside en la posibilidad de interconectar a través de un lenguaje visual a diferentes sistemas, lo que se traduce en la sintaxis de un nuevo lenguaje que se use en todo el mundo, visualmente íntegro que posea colores, formas, líneas, contrastes entre sí, transparencia y configuraciones suficientemente flexibles para mutar cuando así se requiera.

Se describen con ejemplos gráficos a quince técnicas, todas ellas distintas entre sí tal como su objeto y uso se caracteriza: diagrama de arco, agrupación por área, explosión centralizada, anillo centralizado, globo circular, amarres circulares, implosiones elípticas, diagrama de flujo, rizoma orgánico, convergencia radial, implosión radial, ramificación, círculos escalables, convergencia radial segmentada, esfera. 
Decía Blaise Pascal, filósofo francés, que la naturaleza es una esfera infinita en cuyo centro se encuentra el todo y la circunferencia en ningún lugar. A través de la obra, Lima describe cómo las redes han contribuido a mejorar el conocimiento de nuestra concepción como sociedad, cultura y arte a tal grado de expresar un nuevo sentido de belleza. Para ser capaces de encontrar qué nos atrae ante las estructuras visuales habremos de investigar en lo que realmente consiste la noción de una belleza compleja.

Para apreciar las intenciones particulares de componentes individuales no basta únicamente apreciar a los elementos por sí solos, se requiere también tener una combinación de estos ingredientes que permitan encontrar balance e inestabilidad al mismo tiempo que contrastes entre asimetría y simetría, superficie y profundidad, neutralidad y acentos, transparencia y opacidades para que a través de tener la visión del todo se pueda percibir un resultado siempre mayor que la suma de las partes separadas, lo cual resulta en una perspectiva holística.

Sin embargo, si este análisis no permite entonces observar las capacidades individuales fuera de la multitud, aparece el expresionismo abstracto como una asociación vinculada a un movimiento de arte. Para poder apreciar lo que sucede, en nuestra habilidad de percibir la complejidad existe un proceso de resolver lo encriptado de tal forma que sin necesariamente estar conscientes del proceso cognitivo que se desarrolla en el cerebro humano, la naturaleza percibe patrones y los reconoce de manera implícita.

Por otro lado, cuando nos damos cuenta de que los patrones no son necesariamente muy complejos, se pueden reconocer patrones perfectamente alineados y en movimiento, lo cual pudiera parecer complejos a ojos de algunos pero al mismo tiempo ser ordenado para otros; a esta teoría de sistemas dinámicos en los cuales la complejidad no es vista como algo opuesto sino como un conjunto de elementos complementarios de la naturaleza se le conoce como complejidad ordenada. Podemos ser testigos de cómo los elementos de un paisaje pueden representar diversas capas de líneas y conexiones que pudieran dejarnos maravillados ante un sentimiento de integridad basada la noción de complejidad innata cuya unión diversificada se complementa entre sí.

Ante la moda de las redes existentes y su esquema creciente que posee territorios desconocidos, nace el Networkism como una tendencia que estimula la interconectividad en 
múltiples campos de estudio como lo pueden ser la neurociencia, física, biología molecular, sistemas computacionales y sociología; todo esto resulta como cualidades de redes que han sido observadas, cuyos sistemas complejos poseen cualidades intrínsecas de tal forma que logran encontrar un balance entre el orden y desorden, respetando a todas las unidades sin importar su tamaño, ya que cualquiera de ellas podría cambiar todo. La clave de este movimiento, como su nombre lo indica, son las redes, definidas como un conjunto de nodos y uniones que no se limitan a la expresión en dos dimensiones, lo cual provee de un sentido que, según Lima, promueve todas las escalas de la comprensión humana, desde átomos, genes y neuronas hacia ecosistemas, el planeta y el universo. Esto último es una prueba de que a pesar de la complejidad existente dentro de las redes, esta misma complejidad es bella por ser una evocadora fuerza dinámica estructural que incluye orden dentro del desorden, probando que existe unión en la diversidad lo cual resulta un reto para cualquier otra definición de belleza.

Las perspectivas que definen el futuro de la visualización cubren una serie de tendencias y tecnologías que abrirán paso a al progreso. A través de una serie de ensayos, se realizaron pronósticos del uso de la visualización como una herramienta clave en el descubrimiento de un mundo complejo que se encuentra en constante crecimiento de su interconectividad. Mirando hacia adelante es el último capítulo de la obra en donde se pueden conocer a través de distintos autores las expectativas del progreso de tendencia visuales.

Ver el mundo a través de los datos, por Nathan Yau, Doctor egresado en estadística por la UCLA, expone cómo la colección de datos, el análisis y la interacción de datos una vez que la información ha sido procesada pueden brindar interfaces intuitivas a los usuarios que a través de la visualización tienen mayor comprensión de distintos contextos; sin embargo las técnicas visuales son tan importantes como los datos por sí mismos, ya que sin datos no habría nada que analizar y comprender el nuevo mundo.

La caída y despertar de un ambiente de visualización, por Andrew Vande Moere, profesor asociado en el Departamento de Arquitectura de K.U. Leuven en Bélgica, describe el por qué existe una necesidad de exhibir los datos cuando nadie quisiera ser perturbado por el ejercicio. Vande Moere presenta cómo existió una tendencia a la baja en la apreciación y comprensión de valores numéricos que durante los últimos años empezó a cambiar debido 
a una tendencia emergente de conciencia social sobre el uso urgente de tecnología moderna para la explotación de los datos generados mismos que permiten el alcance de objetivos específicos, lo cual cambió la percepción humana sobre la trivialidad de los datos y esta necesidad trasciende al entender el impacto cualitativo de nuestras acciones, disfrutando de la representación visual de la información a la que tenemos acceso.

Cybernética revisada: a través de una inteligencia colectiva, por Christopher Kirwan, Profesor de Psicología en la Universidad de Oxford, comenta que mientras las representaciones tempranas fueron eficientes en resolver problemas de complejidad limitada, no lograban en realidad identificar la influencia del observador en el proceso, para lo cual se podría incorporar a la cibernética lo cual podría brindar un alcance más holístico. Esto gracias a que las aplicaciones cibernéticas pueden extraer los datos por sí solas con acceso abierto a sistemas lo cual le daría al ser humano una mayor capacidad para analizar y prevenir futuras catástrofes antes de que ocurran.

Ecología reflexiva, visualizando prioridades por David McConville, Presidente del Instituto Buckminster Fuller, expone para cerrar la obra que nuestra búsqueda de autorreflexión se ha expandido hacia nuevas dimensiones; la humanidad está incrementando su capacidad de medir y representar de manera temporal, espectral y relacional las características de nuestros ambientes. Expone una reflexión introspectiva ante la aceleración de los cambios globales que nos fuerzan a encontrar nuevas formas de promover la integridad de ecosistemas a través del conocimiento y monitoreo constante para ser capaces de imaginar nuestro lugar en el mundo y, adaptarnos al cambio. 


\section{Sobre el autor}

Manuel Lima es un Diseñador Industrial egresado de la Facultad de Arquitectura por la Universidad Técnica de Lisboa y cuenta con una Maestría en Diseño y Tecnología por la Escuela de Diseño Parsons en New York. Ha trabajado en diseño de productos digitales, para Microsoft, Nokia, R/GA y Kontrapunkt. Ha colaborado para el Centro de Investigación Corporativa de Siemens, el Museo Americano de la Imagen en Movimiento y el Instituto Parsons para Mapeo de Información. Adicional a la obra Visual Complexity: Mapping Patterns of Information, Lima ha publicado en el 2014 The Book of trees: Visualizing Branches of Knowledge. ${ }^{2}$ 